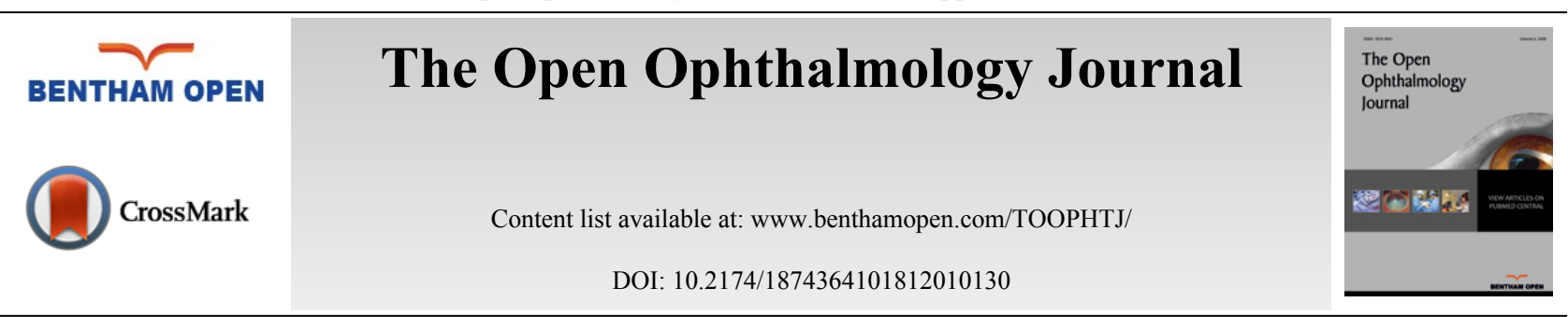

\title{
EDITORIAL
}

\section{Advances in Cornea}

Recent advances in corneal practice \& research have largely been centered around interests concerning the endothelial keratoplasty, corneal biomechanics and collagen cross linking of the corneal stroma. This special issue of OPEN OPHTHALMOLOGY JOURNAL addresses these interests with an elaboration of the outcomes of endothelial keratoplasty procedures of Descemet's Membrane Endothelial Keratoplasty (DMEK) and Pre-Descemet's Endothelial Keratoplasty (PDEK), a perspective on future potent therapies for Fuch's Endothelial Corneal Dystrophy (FECD), a comprehensive review on corneal biomechanics in LASIK and Small Incision Lenticule Extraction (SMILE) and on practical applications of collagen cross linking along with the outcomes of Lasik Xtra.

Since, the introduction of the concept of Descemet's membrane endothelial keratoplasty by Melles et al. in 2002 [1], the rapid time to visual rehabilitation has made it the more preferred endothelial keratoplasty procedure. Several techniques have been described for harvesting the donor graft for DMEK procedure. Following a 9 mm trephination of the Descemet's Membrane (DM), peripheral scoring was facilitated by forceps, Sinskey hook or blade, and peeling being completed by a single or double non-toothed forceps, with the graft remaining immersed in the preservative media in the viewing chamber $[2,3]$. The required size trephination of the DM was then done. The success rates of DMEK graft preparation vary with the tissue preparation in eye bank or by experienced surgeons [3 - 5]. Marking of the edge of the DM graft with orientation marks, the blue cannula sign, hand held slit bean, intra operative OCT aided surgery, ink marks on the DM side of the graft have all been elucidated to ensure the right orientation while positioning the DM graft within the eye [6 - 12]. Reported endothelial cell loss rates range from 25 to $53 \%$ over long term follow up and air injection rates varying from $13-82 \%$, primary graft failure rate of 0.1 to $12.5 \%$, graft rejection rates of 0.8 to $5.1 \%$ have also been noted in various studies on DMEK [13]. Graft detachments, secondary glaucoma and cystoids macular edema after DMEK are also a cause of concern. In this issue, Basak et al. have described the results of DMEK in their first 100 cases using surgeon prepared DMEK roll prepared by a simplified technique. The excellent results obtained seem to stem from the fact that the surgeon was already an experienced Descemet's stripping endothelial keratoplasty surgeon, with capitalization on the knowledge gained over the reported results of the experiences of various other clinicians combined with standardization of technique.

PDEK is a novel endothelial keratoplasty technique in which the composite of pre-Descemet's stromal layer (Dua's layer) with DM and endothelium is transplanted subsequently to the removal of the recipient's DM [14]. The scrolling characteristics of the pre-descemetic layer have been attributed to influence tissue preparation, handling, and unscrolling in the eye during the endothelial keratoplasty [15]. This technique has been described to enable the use of infant donor cornea for endothelial keratoplasty facilitating donor lenticule preparation, insertion of the donor graft, or air bubble management without any difficulty [16]. The continuous pressurized air infusion using an air pump-assisted technique has been described earlier to enable good graft positioning and adherence apart from also providing optimal tamponade to stop hemorrhage during the peripheral iridectomy, increasing surgical space and maintaining anterior chamber depth and anterior chamber depth [17]. In this issue, the use of continuous pressurized air infusion from the fluid air exchange system of a posterior vitrectomy machine for multiple key steps of PDEK surgery such as descemetorhexis, Peripheral Iridectomy (PI), graft floatation, graft centration, graft edge unfolding, graft un-wrinkling and graft adhesion is being evaluated by Jacob S in PDEK surgery.

For over a long period of time, endothelial transplantation seemed to be the only option for the treatment of Fuch's endothelial corneal dystrophy. FECD has been categorized into three types (i) as early-onset FECD, (ii) as identified genetic loci, and (iii) disease without known inheritance [18]. Missense mutation of the COL8A2 gene on chromosome 
1 p34.3-p32 has been identified in early onset FECD and genetic mutations in four genes (SLCA411, TCF8, LOXHD1, and AGBL1) were reported as causal factors as well [19 - 24]. The article by Okamura et al. explores the current strategies on the use of cultures corneal endothelial cells either as sheets for transplantation or by direct injection of cultured corneal endothelial cells in the anterior chamber as therapeutic interventions. The success of obtaining regeneration of the corneal endothelium by co-injecting cultured corneal endothelial cells along with ROCK inhibitor into anterior chamber in animal studies has prompted their team to further research in human eyes [25]. This review is a vivid elucidation of the future therapies for FECD.

With increasing popularity of SMILE procedure as a flapless and minimally invasive form of Laser Vision Correction (LVC) for the treatment of myopia and myopic astigmatism, the debate on its effects on corneal biomechanics in comparison to other LVC procedures is being widely investigated. Studies on the long-term outcomes of SMILE point towards its superior performance which shows excellent stability for higher myopia. SMILE also seems to have an advantage in terms of dry eye occurrence postoperatively over LASIK with better Schirmer's, tear film break up time, corneal sensitivity, and corneal nerve regeneration following SMILE as compared to LASIK [26]. The intact Bowman's Membrane (BM) and the corneal anterior stromal lamellae in SMILE procedure may perhaps be responsible for better corneal biomechanics over LASIK and PRK procedures. The flap-based LASIK and Refractive Lenticule Extraction (ReLEx) and flap-free ReLEx smile were noted by Pedersen et al. to result in a similar reduction in corneal biomechanics when evaluated by Corvis ST and ORA [27]. The decrease in corneal biomechanics was seen to be lesser in SMILE than with LASIK in myopia greater than -6.00 D [28]. Agca et al. found a decrease in Corneal Hysteresis $(\mathrm{CH})$ and Corneal Resistance Factor (CRF) in SMILE and did not find differences in postoperative CH or CRF values between SMILE and femto-LASIK treatments [29]. However, considering that there seem to be conflicting reports on this in recent literature [30 - 34], the evidence on corneal biomechanics affection being less in SMILE is still inconclusive. In this issue, Iben et al. discuss the review of corneal biomechanical properties following LASIK and SMILE for myopia and myopic astigmatism.

This issue also covers a comprehensive review on current trends in practical applications of corneal collagen crosslinking which is a subject of interest to all in corneal practice in recent times. LASIK Xtra is a recently described technique which combines LASIK and accelerated CXL performed simultaneously in the same sitting. Lasik Xtra is thought to afford early stabilization of the cornea after LASIK, and enhance the predictability of refractive outcomes in highly myopic eyes [35 - 36]. Lim Li et al. also discuss their outcome of simultaneous accelerated corneal cross linking and laser in situ keratomileusis for the treatment of high myopia.

\section{REFERENCES}

[1] Melles GR, Lander F, Rietveld FJ. Transplantation of Descemet's membrane carrying viable endothelium through a small scleral incision. Cornea 2002; 21(4): 415-8. [http://dx.doi.org/10.1097/00003226-200205000-00016] [PMID: 11973393]

[2] Price MO, Giebel AW, Fairchild KM, Price FW Jr. Descemet's membrane endothelial keratoplasty: Prospective multicenter study of visual and refractive outcomes and endothelial survival. Ophthalmology 2009; 116(12): 2361-8. [http://dx.doi.org/10.1016/j.ophtha.2009.07.010] [PMID: 19875170]

[3] Laaser K, Bachmann BO, Horn FK, Schlötzer-Schrehardt U, Cursiefen C, Kruse FE. Donor tissue culture conditions and outcome after descemet membrane endothelial keratoplasty. Am J Ophthalmol 2011; 151(6): 1007-1018.e2. [http://dx.doi.org/10.1016/j.ajo.2010.11.027] [PMID: 21334592]

[4] Vianna LM, Stoeger CG, Galloway JD, et al. Risk factors for eye bank preparation failure of Descemet membrane endothelial keratoplasty tissue. Am J Ophthalmol 2015; 159(5): 829-34.e2.

[http://dx.doi.org/10.1016/j.ajo.2015.01.030] [PMID: 25640409]

[5] Schlötzer-Schrehardt U, Bachmann BO, Tourtas T, et al. Reproducibility of graft preparations in Descemet's membrane endothelial keratoplasty. Ophthalmology 2013; 120(9): 1769-77. [http://dx.doi.org/10.1016/j.ophtha.2013.06.038] [PMID: 23870299]

[6] Kruse FE, Laaser K, Cursiefen C, et al. A stepwise approach to donor preparation and insertion increases safety and outcome of Descemet membrane endothelial keratoplasty. Cornea 2011; 30(5): 580-7. [http://dx.doi.org/10.1097/ICO.0b013e3182000e2e] [PMID: 21598430]

[7] Deng SX, Sanchez PJ, Chen L. Clinical outcomes of Descemet membrane endothelial keratoplasty using eye bank-prepared tissues. Am J Ophthalmol 2015; 159(3): 590-6.

[http://dx.doi.org/10.1016/j.ajo.2014.12.007] [PMID: 25526945]

[8] Güell JL, Morral M, Gris O, Elies D, Manero F. Comparison of sulfur hexafluoride 20\% versus air tamponade in Descemet membrane endothelial keratoplasty. Ophthalmology 2015; 122(9): 1757-64. 
[http://dx.doi.org/10.1016/j.ophtha.2015.05.013] [PMID: 26088620]

[9] Burkhart ZN, Feng MT, Price MO, Price FW. Handheld slit beam techniques to facilitate DMEK and DALK. Cornea 2013; 32(5): 722-4 [http://dx.doi.org/10.1097/ICO.0b013e31827797e7] [PMID: 23407317]

[10] Ehlers JP, Goshe J, Dupps WJ, et al. Determination of feasibility and utility of microscope-integrated optical coherence tomography during ophthalmic surgery: The DISCOVER Study RESCAN Results. JAMA Ophthalmol 2015; 133(10): 1124-32. [http://dx.doi.org/10.1001/jamaophthalmol.2015.2376] [PMID: 26226623]

[11] Veldman PB, Dye PK, Holiman JD, et al. The S-stamp in Descemet membrane endothelial keratoplasty safely eliminates upside-down graft implantation. Ophthalmology 2016; 123(1): 161-4.

[http://dx.doi.org/10.1016/j.ophtha.2015.08.044] [PMID: 26439215]

[12] Deng SX, Lee WB, Hammersmith KM, et al. Descemet membrane endothelial keratoplasty: Safety and outcomes: A report by the american academy of ophthalmology. Ophthalmology 2018; 125(2): 295-310. [http://dx.doi.org/10.1016/j.ophtha.2017.08.015] [PMID: 28923499]

[13] Agarwal A, Dua HS, Narang P, et al. Pre-Descemet's Endothelial Keratoplasty (PDEK). Br J Ophthalmol 2014; 98(9): 1181-5. [http://dx.doi.org/10.1136/bjophthalmol-2013-304639] [PMID: 24659352]

[14] Dua HS, Termote K, Kenawy MB, et al. Scrolling characteristics of pre-descemet endothelial keratoplasty tissue: An ex vivo study. Am J Ophthalmol 2016; 166: 84-90. [http://dx.doi.org/10.1016/j.ajo.2016.03.034] [PMID: 27038891]

[15] Agarwal A, Agarwal A, Narang P, Kumar DA, Jacob S. Pre-descemet endothelial keratoplasty with infant donor corneas: A prospective analysis. Cornea 2015; 34(8): 859-65.

[http://dx.doi.org/10.1097/ICO.0000000000000486] [PMID: 26057329]

[16] Jacob S, Narasimhan S, Agarwal A, Agarwal A, A i S. Air pump-assisted graft centration, graft edge unfolding, and graft uncreasing in young donor graft pre-descemet endothelial keratoplasty. Cornea 2017; 36(8): 1009-13. [http://dx.doi.org/10.1097/ICO.0000000000001225] [PMID: 28481833]

[17] Weiss JS, Moller HU, Aldave AJ, Seitz B, Bredrup C, Kivela T, et al. IC3D classification of corneal dystrophies--edition 2. In: Cornea. 2015; 34: pp. 117-59.

[18] Riazuddin SA, Zaghloul NA, Al-Saif A, et al. Missense mutations in TCF8 cause late-onset Fuchs corneal dystrophy and interact with FCD4 on chromosome 9p. Am J Hum Genet 2010; 86(1): 45-53. [http://dx.doi.org/10.1016/j.ajhg.2009.12.001] [PMID: 20036349]

[19] Vithana EN, Morgan PE, Ramprasad V, et al. SLC4A11 mutations in Fuchs endothelial corneal dystrophy. Hum Mol Genet 2008; 17(5): 656-66.

[http://dx.doi.org/10.1093/hmg/ddm337] [PMID: 18024964]

[20] Riazuddin SA, Vithana EN, Seet LF, et al. Missense mutations in the sodium borate cotransporter SLC4A11 cause late-onset Fuchs corneal dystrophy. Hum Mutat 2010; 31(11): 1261-8. [http://dx.doi.org/10.1002/humu.21356] [PMID: 20848555]

[21] Mehta JS, Vithana EN, Tan DT, et al. Analysis of the posterior polymorphous corneal dystrophy 3 gene, TCF8, in late-onset Fuchs endothelial corneal dystrophy. Invest Ophthalmol Vis Sci 2008; 49(1): 184-8. [http://dx.doi.org/10.1167/iovs.07-0847] [PMID: 18172091]

[22] Riazuddin SA, Parker DS, McGlumphy EJ, et al. Mutations in LOXHD1, a recessive-deafness locus, cause dominant late-onset Fuchs corneal dystrophy. Am J Hum Genet 2012; 90(3): 533-9.

[http://dx.doi.org/10.1016/j.ajhg.2012.01.013] [PMID: 22341973]

[23] Riazuddin SA, Vasanth S, Katsanis N, Gottsch JD. Mutations in AGBL1 cause dominant late-onset Fuchs corneal dystrophy and alter proteinprotein interaction with TCF4. Am J Hum Genet 2013; 93(4): 758-64. [http://dx.doi.org/10.1016/j.ajhg.2013.08.010] [PMID: 24094747]

[24] Okumura N, Sakamoto Y, Fujii K, et al. Rho kinase inhibitor enables cell-based therapy for corneal endothelial dysfunction. Sci Rep 2016; 6: 26113. [http://dx.doi.org/10.1038/srep26113] [PMID: 27189516]

[25] Ganesh S, Brar S, Arra RR. Refractive lenticule extraction small incision lenticule extraction: A new refractive surgery paradigm. Indian J Ophthalmol 2018; 66(1): 10-9.

[http://dx.doi.org/10.4103/ijo.IJO_761_17] [PMID: 29283117]

[26] Pedersen IB, Bak-Nielsen S, Vestergaard AH, Ivarsen A, Hjortdal J. Corneal biomechanical properties after LASIK, ReLEx flex, and ReLEx smile by Scheimpflug-based dynamic tonometry. Graefes Arch Clin Exp Ophthalmol 2014; 252(8): 1329-35. [http://dx.doi.org/10.1007/s00417-014-2667-6] [PMID: 24862302]

[27] Wang D, Liu M, Chen Y, et al. Differences in the corneal biomechanical changes after SMILE and LASIK. J Refract Surg 2014; 30(10): $702-7$. [http://dx.doi.org/10.3928/1081597X-20140903-09] [PMID: 25291754]

[28] Agca A, Ozgurhan EB, Demirok A, et al. Comparison of corneal hysteresis and corneal resistance factor after small incision lenticule extraction and femtosecond laser-assisted LASIK: a prospective fellow eye study. Cont Lens Anterior Eye 2014; 37(2): 77-80. 
[http://dx.doi.org/10.1016/j.clae.2013.05.003] [PMID: 23830802]

[29] Wang B, Zhang Z, Naidu RK, et al. Comparison of the change in posterior corneal elevation and corneal biomechanical parameters after small incision lenticule extraction and femtosecond laser-assisted LASIK for high myopia correction. Cont Lens Anterior Eye 2016; 39(3): 191-6.

[http://dx.doi.org/10.1016/j.clae.2016.01.007] [PMID: 26852167]

[30] Osman IM, Helaly HA, Abdalla M, Shousha MA. Corneal biomechanical changes in eyes with small incision lenticule extraction and laser assisted in situ keratomileusis. BMC Ophthalmol 2016; 16: 123. [http://dx.doi.org/10.1186/s12886-016-0304-3] [PMID: 27457241]

[31] Zhang J, Zheng L, Zhao X, Xu Y, Chen S. Corneal biomechanics after small-incision lenticule extraction versus Q-value-guided femtosecond laser-assisted in situ keratomileusis. J Curr Ophthalmol 2016; 28(4): 181-7. [http://dx.doi.org/10.1016/j.joco.2016.08.004] [PMID: 27830201]

[32] Kanellopoulos AJ. Comparison of corneal biomechanics after myopic small-incision lenticule extraction compared to LASIK: an ex vivo study. Clin Ophthalmol 2018; 12(12): 237-45. [http://dx.doi.org/10.2147/OPTH.S153509] [PMID: 29416315]

[33] Kling S, Spiru B, Hafezi F, Sekundo W. Biomechanical weakening of different re-treatment options after Small Incision Lenticule Extraction (SMILE). J Refract Surg 2017; 33(3): 193-8. [http://dx.doi.org/10.3928/1081597X-20161221-01] [PMID: 28264134]

[34] Kanellopoulos AJ, Pamel GJ. Review of current indications for combined very high fluence collagen cross-linking and laser.in situ keratomileusis surgery. Indian J Ophthalmol 2013; 61(8): 430-2. [http://dx.doi.org/10.4103/0301-4738.116074] [PMID: 23925331]

[35] Kanellopoulos AJ, Asimellis G, Karabatsas C. Comparison of prophylactic higher fluence corneal cross-linking to control, in myopic LASIK, one year results. Clin Ophthalmol 2014; 8: 2373-81. [http://dx.doi.org/10.2147/OPTH.S68372]

[36] Tan J, Lytle GE, Marshall J. Consecutive laser in situ keratomileusis and accelerated corneal crosslinking in highly myopic patients: preliminary results. 2014 Nov 27;8:2373-81. Eur J Ophthalmol 2014.

[http://dx.doi.org/10.5301/ejo.5000543]

M. Vanathi

Cornea \& Ocular Surface, Cataract \& Refractive Services

R. P. Centre for Ophthalmic Sciences

All India Institute Of Medical Sciences

New Delhi 110029, India

Fax: 91-11-26588919

E-mail: mvanathi.rpc@gmail.com

C) 2018 M. Vanathi.

This is an open access article distributed under the terms of the Creative Commons Attribution 4.0 International Public License (CC-BY 4.0), a copy of which is available at: (https://creativecommons.org/licenses/by/4.0/legalcode). This license permits unrestricted use, distribution, and reproduction in any medium, provided the original author and source are credited. 